\title{
Effect of Prolonged-Release Pirfenidone on Renal Function in Septic Acute Kidney Injury Patients: A Double-Blind Placebo-Controlled Clinical Trial
}

\author{
Jonathan S. Chávez-Iñiguez $\mathbb{D},{ }^{1,2}$ Jorge L. Poo, ${ }^{3}$ Miguel Ibarra-Estrada $\mathbb{D}^{4},{ }^{4}$ \\ Leonel García-Benavides, ${ }^{2,5}$ Guillermo Navarro-Blackaller ${ }^{1 D},{ }^{1,2}$ \\ Cynthia Cervantes-Sánchez, ${ }^{1,2}$ Eduardo Nungaray-Pacheco, ${ }^{1,2}$ \\ Ramón Medina-González (iD, ${ }^{1,2}$ Juan Armendariz-Borunda ${ }^{(D)},{ }^{2,6,7}$ \\ and Guillermo García-García ${ }^{1,2}$ \\ ${ }^{1}$ Servicio de Nefrología, Hospital Civil de Guadalajara Fray Antonio Alcalde, Guadalajara, Jalisco, Mexico \\ ${ }^{2}$ Universidad de Guadalajara, Centro Universitario de Ciencias de La Salud CUCS, Guadalajara, Jalisco, Mexico \\ ${ }^{3}$ Unidad de Investigación, ITESM-CCM, Mexico City, Mexico \\ ${ }^{4}$ Servicio de Unidad de Terapia Intensiva, Hospital Civil de Guadalajara Fray Antonio Alcalde, Guadalajara, Jalisco, Mexico \\ ${ }^{5}$ Universidad de Guadalajara, Centro Universitario de Tonalá CUTonalá, Tonalá, Jalisco, Mexico \\ ${ }^{6}$ Instituto de Biología Molecular en Medicina, CUCS, Universidad de Guadalajara, Guadalajara, Jalisco, Mexico \\ ${ }^{7}$ Tecnologico de Monterrey, Campus Guadalajara, Monterrey, Mexico
}

Correspondence should be addressed to Juan Armendariz-Borunda; armdbo@gmail.com

Received 5 September 2020; Revised 27 December 2020; Accepted 4 January 2021; Published 13 January 2021

Academic Editor: Franca Anglani

Copyright (c) 2021 Jonathan S. Chávez-Iñiguez et al. This is an open access article distributed under the Creative Commons Attribution License, which permits unrestricted use, distribution, and reproduction in any medium, provided the original work is properly cited.

\begin{abstract}
Background. There is no treatment for septic acute kidney injury (sAKI). The anti-inflammatory activity of prolonged-release pirfenidone (PR-PFD) could be beneficial in this clinical setting. Methods. This study was a double-blind randomized clinical trial in sAKI patients with nephrology consultation at the Civil Hospital of Guadalajara, in addition to the usual treatment of AKI associated with sepsis; patients were randomized to receive either PR-PFD at 1,200 mg/day (group A) or $600 \mathrm{mg} / \mathrm{day}$ (group B) or a matched placebo for 7 consecutive days. The primary objective was the decrease in serum creatinine $(\mathrm{sCr})$ and increase in urinary volume (UV); the secondary objectives were changes in serum electrolytes, acid-base status, and mortality. Results. Between August 2016 and August 2017, 88 patients were randomized. The mean age was 54 (17 \pm SD) years, and $47 \%$ were male. The main site of infection was the lung (39.8\%), septic shock was present in $39.1 \%$ of the cases, and the mean SOFA score was 8.8 points. 28 patients received PFD 1,200 mg, 30 patients received PFD $600 \mathrm{mg}$, and 30 patients received placebo. During the study, sCr did not differ among the groups. The reversion rate of $\mathrm{sCr}, \mathrm{UV}$, and mortality was not different among the groups $(p=0.70, p=0.47$, and $p=0.38$, respectively). Mild adverse events were not different among the groups. Conclusion. PR-PFD did not improve the clinical course of sAKI and seemed to be safe in terms of adverse events. This trial is registered with NCT02530359.
\end{abstract}

\section{Introduction}

Acute kidney injury (AKI) is a serious medical complication that is independently associated with poor outcomes $[1,2]$. Approximately one out of five nonsevere sepsis patients develop AKI [3], increasing to two-thirds in critically ill patients [4-9]. Approximately $50 \%$ of ICU patients with AKI die, and those who survive an AKI episode have an increased risk of progressing to chronic kidney disease (CKD) [10-12]. Currently, there are few pharmacological therapeutic options available to prevent or treat AKI, and management is limited to alleviate 
secondary hemodynamic and toxic renal insults and to provide supportive measures, such as dialysis.

Although AKI can be caused by a variety of factors [10], sepsis is the most important etiology [13]. Sepsis-associated AKI (sAKI) is distinct from nonsepsis AKI in terms of pathogenesis, patient characteristics, and clinical outcomes [13-15]. sAKI is more frequent, more severe, less likely to resolve once AKIN stage 3 develops, and associated with higher mortality [16]. It has been suggested that glomerular ultrafiltration of toxic blood is the inciting mechanism for tubular stress and subsequent tubular damage [17]. According to this hypothesis, during sepsis, the glomerular filtrate is loaded with cytokines, chemokines, and complement fragments, which may have a toxic effect on tubular cells [18]. This "inflammatory" hypothesis of AKI is supported by experimental observations [19]. Renal responses to inflammation may be directed to decrease energy consumption by autophagy, digestion, mitochondrial dysfunction (mitophagy), and loss of cell polarity [20]. How these complex inflammatory events affect renal function remains unknown. Therefore, there is a need for additional interventions that could improve AKI prognosis [21]. Experimental studies support anti-inflammatory and positive effects induced by PFD in different AKI models [22-26]. In this study, we examined the effects of PR-PFD on renal function in sAKI patients in a double-blind, randomized, clinical trial.

\section{Materials and Methods}

This study was a randomized, double-blind, parallel-design clinical trial conducted in a single university hospital. The population of the study consisted of hospitalized septic AKI patients. AKI was diagnosed by the serum creatinine $(\mathrm{sCr}$ ) KDIGO criteria [27]; sepsis was defined according to the Surviving Sepsis-3 campaign [28]. Septic patients with AKI aged $\geq 18$ and $<85$ years, having baseline creatinine $<2 \mathrm{mg}$ / $\mathrm{dL}$, and with written informed consent were included; patients with CKD (basal serum creatinine $>2 \mathrm{mg} / \mathrm{dl}$ ) stage $3 \mathrm{~b}$, 4 , or 5 , on chronic dialysis, with a history of AKI, or with renal replacement therapy within the last 3 months and pregnant individuals were excluded. In addition to standard AKI treatment, patients were randomly assigned to 3 study groups: group A, oral $1200 \mathrm{mg}$ of PR-PFD every 12 hours for 7 consecutive days; group B, $600 \mathrm{mg}$ of PR-PFD in the morning and a matched placebo at night for 7 consecutive days; and group $\mathrm{C}$, a matched placebo orally every 12 hours for 7 consecutive days. The primary objective was the decrease in serum creatinine $(\mathrm{sCr})$ and increase in urinary volume (UV); the secondary objectives were changes in serum electrolytes, acid-base status, and mortality. Sample size was not determined because this intervention was never tried before. The randomization process was carried out in Excel software in a $1: 1: 1$ fashion, and nephrology staff members blinded to the allocation groups administered the drugs to each patient every day. All patients had a detailed clinical history and physical examination that included the measurement of blood pressure, heart and respiratory rates, oxygen saturation, ventilatory parameters in patients with mechanically assisted ventilation, and strict fluid balance. Complete blood count, serum creatinine ( $\mathrm{sCr}$ ), serum urea, BUN, serum electrolytes, and urinalysis parameters were measured on a daily basis. The study was approved by the Hospital Civil de Guadalajara Fray Antonio Alcalde Ethics Committee (HCG/CI-0049/15) and by Comision Federal para la Proteccion de Riesgos Sanitarios (COFEPRIS), México, both in June 2016. Written informed consent was obtained from all study participants. The trial was presented according to the CONSORT 2010 Explanation and Elaboration guide.

2.1. Statistical Analysis. Continuous variables are presented as the mean $( \pm S D)$ when normally distributed or as medians (interquartile range (IQR)) in the case of abnormal distribution, following the Shapiro-Wilk test. One-way ANOVA was used to compare differences between groups. Categorical variables are expressed as proportions and were compared with Fisher's chi-square or exact test as appropriate. For the rest of the tests, the $p$ values were two-tailed; a $p<0.05$ was considered statistically significant. Statistical analysis and graphs were produced with MedCalc statistical software version 19.1.3 (Ostend, Belgium).

\section{Results}

Between August 2016 and August 2017, a total of 268 patients were assessed for eligibility; one hundred eighty patients did not meet the inclusion criteria, and 88 were randomized: 28 in group $A$ (PFD, 1,200 mg), 30 in group B (PFD, $600 \mathrm{mg}$ ), and 30 in group $\mathrm{C}$ (placebo) (Figure 1). The baseline characteristics of the study patients are shown in Table 1; the mean age was $54( \pm$ SD) years, and $47 \%$ were male. The most common infection site was the lung (39.8\%), and septic shock was present in $39.1 \%$ of the cases. Nonsurgical cases were frequent in our study population $(60.2 \%)$. Mechanical ventilation was used in $29.5 \%$ of the patients, and the mean SOFA score was 8.8 points. The time elapsing from hospitalization to randomization was 6.9 hours (Table 1).

The AKI trajectory by $\mathrm{sCr}$ during the intervention is presented in Figure 2(a). A tendency toward improvement in sCr was observed in all groups, but it was not significantly different $(p=0.71)$ throughout the treatment period. However, in the intragroup analysis, $\mathrm{sCr}$ decreased significantly in group B $(3.0 \mathrm{mg} / \mathrm{dL}$ to $1.7 \mathrm{mg} / \mathrm{dL}, p=0.01)$ and in group C $(2.6 \mathrm{mg} / \mathrm{dL}$ to $1.2 \mathrm{mg} / \mathrm{dL}, p=0.01)$ but not in group $\mathrm{A}(2.9 \mathrm{mg} / \mathrm{dL}$ to $1.8 \mathrm{mg} / \mathrm{dL}, p=0.26)$. The $\mathrm{sCr}$ reversion rate, defined as a decrease in sCr to $\leq 30 \%$ from baseline at any time during hospitalization, was similar in all groups $(60.7 \%$, $50 \%$, and $53.3 \%$ in groups $\mathrm{A}, \mathrm{B}$, and $\mathrm{C}$, respectively, $p=0.70)$. The AKI course by urine volume during the intervention is presented in Figure 2(b). UV decreased in all groups, but the change was not statistically significant (from $1,478 \mathrm{ml} /$ day to $1,362 \mathrm{ml} /$ day $(p=0.55)$ in group $\mathrm{A}$; from $1,455 \mathrm{ml} /$ day from $1,420 \mathrm{ml} /$ day $(p=0.98)$ in group $B$; and from $1,732 \mathrm{ml} /$ day to $2,364 \mathrm{ml} /$ day $(p=0.28)$ in group $\mathrm{C})$. Intermittent hemodialysis (IHD) was required in $14(16 \%)$ 


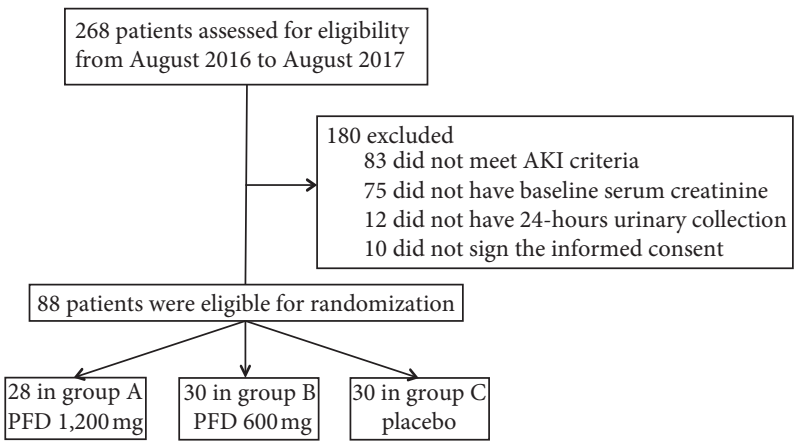

FIgURE 1: Flowchart of the study patients.

TABle 1: Demographic and clinical characteristics of patients.

\begin{tabular}{|c|c|c|c|c|}
\hline & Group A, $n=28$ & Group B, $n=30$ & Group C, $n=30$ & $p$ \\
\hline Male (\%) & $15(53.6)$ & $14(46.7)$ & $13(43.3)$ & 0.73 \\
\hline Age (years) & $55 \pm 19.6$ & $54 \pm 15.7$ & $53 \pm 17.2$ & 0.85 \\
\hline Sepsis site (\%) & & & & 0.64 \\
\hline Pulmonary & $9(32.1)$ & $12(40)$ & $14(46.7)$ & \\
\hline Gastrointestinal & $6(21.4)$ & $3(10)$ & $4(13.3)$ & \\
\hline Urinary & $5(17.9)$ & $5(16.7)$ & $4(13.3)$ & \\
\hline Soft tissue & $7(25)$ & $7(23.3)$ & $7(23.3)$ & \\
\hline Central nervous system & $1(3.6)$ & 0 & 0 & \\
\hline Others & 0 & $3(10)$ & $1(3.3)$ & \\
\hline Comorbidities (\%) & & & & 0.71 \\
\hline Neoplasia & $1(3.6)$ & $4(13.3)$ & $4(13.3)$ & \\
\hline HIV & $3(10.7)$ & $3(10)$ & $2(6.7)$ & \\
\hline COPD & 0 & 0 & $1(3.3)$ & \\
\hline $\mathrm{CHF}$ & $1(3.6)$ & $2(6.7)$ & $3(10)$ & \\
\hline $\mathrm{DM}(\%)$ & $10(35.7)$ & $16(53.3)$ & $7(23.3)$ & 0.05 \\
\hline Hypertension (\%) & $8(28.6)$ & $16(53.3)$ & $12(40)$ & 0.15 \\
\hline Baseline sCr (mg/dL) & $0.81 \pm 0.33$ & $0.87 \pm 0.29$ & $0.78 \pm 0.24$ & 0.48 \\
\hline sCr on day $1(\mathrm{mg} / \mathrm{dL})$ & $3.0 \pm 1.7$ & $3.3 \pm 3.1$ & $2.7 \pm 1.6$ & 0.60 \\
\hline Oligoanuria (\%) & $3(10.7)$ & $7(23.3)$ & $6(20)$ & 0.43 \\
\hline Septic shock (\%) & $11(39.3)$ & $10(34.5)$ & $13(43.3)$ & 0.78 \\
\hline Cardiogenic shock (\%) & $4(14.3)$ & $7(23.3)$ & $3(10)$ & 0.35 \\
\hline Surgical case $(\%)$ & $13(46.4)$ & $14(46.7)$ & $8(26.7)$ & 0.19 \\
\hline Mechanical ventilation (\%) & $10(35.7)$ & $6(20)$ & $10(33.3)$ & 0.36 \\
\hline Randomization time (h) & $6.6 \pm 7$ & $5.5 \pm 6.7$ & $8.5 \pm 11.7$ & 0.40 \\
\hline SOFA score & $9 \pm 2.3$ & $8.7 \pm 2.5$ & $8.9 \pm 2.5$ & 0.84 \\
\hline
\end{tabular}

HIV: human immunodeficiency virus; COPD: chronic obstructive pulmonary disease; CHF: chronic heart failure; DM2: diabetes mellitus.

patients. In group $\mathrm{A}$, two (7.1\%) patients needed IHD; in group B, 6 (20\%) patients needed IHD; and in group C, 6 (20\%) patients needed IHD. However, the differences were not statistically significant $(p=0.30)$. The acid-base status, electrolytes, and other variables during the study period are shown in Table 2. Significant changes in serum $\mathrm{pH}$, serum potassium, and blood hemoglobin were observed only in group B.

Adherence was defined as the intake of the drug/placebo tablets for $>80 \%$ of the intakes (in total 14 during the 7 days) which was similar among all groups $(p=0.71)$. In $82 \%, 93 \%$, and $80 \%$ of the cases, they met the adherence criteria in groups $\mathrm{A}, \mathrm{B}$, and $\mathrm{C}$, respectively. No patient required study drug discontinuation during the study.

Adverse events were similar among the groups: $42.9 \%$ in group $\mathrm{A}, 43.3 \%$ in group $\mathrm{B}$, and $30 \%$ in group $\mathrm{C}$ $(p=0.48)$, the most common being gastrointestinal discomfort (18\%), hyperuricemia (9\%), and rash $(7 \%)$. Twenty-two (25\%) patients died during the study, $9(32.1 \%)$ patients in group A, $8(26.7 \%)$ patients in group B, and 5 (16.7\%) patients in group C (Figure 3), and the majority (77\%) died within the first 7 days $(n=17)$ of follow-up. A total of $10(45.4 \%)$ patients died in the ICU. The mortality rate was not different among the groups $(p=0.38)$. Patients who received $\mathrm{PFD}$ at any dose had a nonsignificant $(p=0.21)$ risk ratio for death of 1.1 (95\% CI $0.93-1.48)$ compared to patients in placebo.

\section{Discussion}

In this single-center, double-blind, randomized control trial conducted in septic AKI patients, PR-PFD at two different dosages did not improve kidney function compared to that with the placebo. However, a significant intragroup 


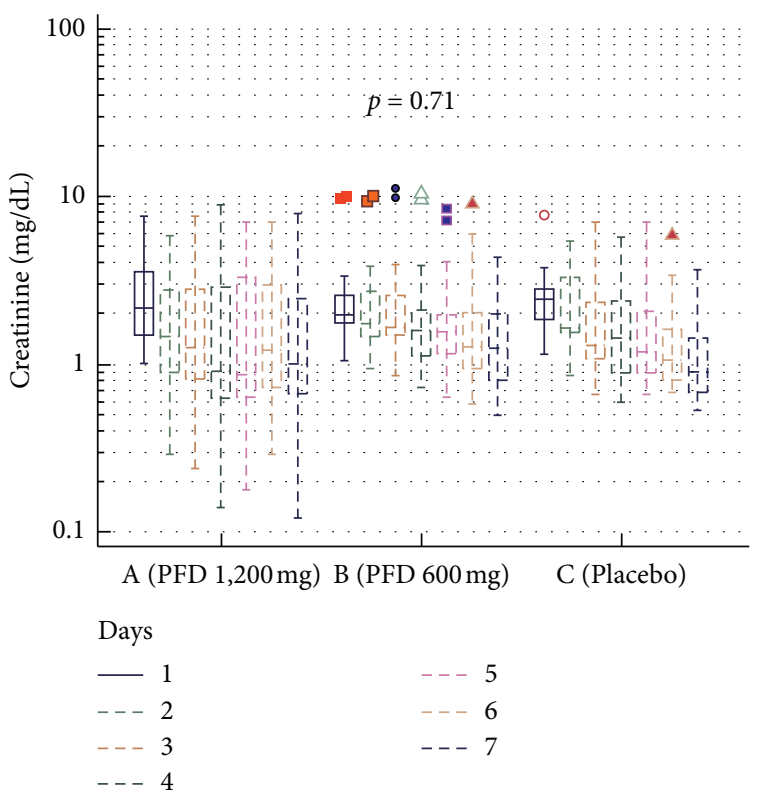

(a)

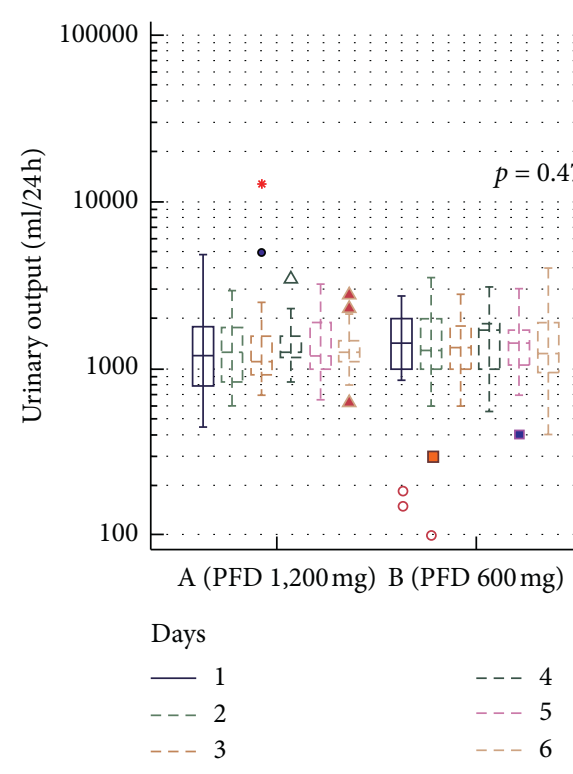

(b)

FIGURE 2: AKI trajectory during the intervention period by sCr (a) and UV (b) according to randomization groups.

TABLe 2: Variables of the study from day 1 compared to day 7 according to the study group.

\begin{tabular}{|c|c|c|c|c|}
\hline & Group A, $n=28$ & Group B, $n=30$ & Group C, $n=30$ & $p$ \\
\hline Serum $\mathrm{pH}$ day 1 & $7.38 \pm 0.08$ & $7.35 \pm 0.07$ & $7.32 \pm 0.1$ & 0.10 \\
\hline Serum $\mathrm{pH}$ day 7 & $7.39 \pm 0.06$ & $7.38 \pm 0.05$ & $7.40 \pm 0.07$ & 0.67 \\
\hline$p$ value & 1.0 & 0.01 & 0.23 & \\
\hline Serum $\mathrm{HCO}^{3-}(\mathrm{mEq} / \mathrm{L})$ day 1 & $21.1 \pm 5.4$ & $21.3 \pm 5.0$ & $21 \pm 4.5$ & 0.96 \\
\hline Serum $\mathrm{HCO}^{3-}(\mathrm{mEq} / \mathrm{L})$ day 7 & $23.2 \pm 4.5$ & $21.9 \pm 4.1$ & $24.8 \pm 4.8$ & 0.20 \\
\hline$p$ value & 0.18 & 0.30 & 0.08 & \\
\hline Serum $K(\mathrm{mEq} / \mathrm{L})$ day 1 & $4.1 \pm 0.9$ & $4.4 \pm 1.2$ & $4.3 \pm 1.5$ & 0.79 \\
\hline Serum $K(\mathrm{mEq} / \mathrm{L})$ day 7 & $3.6 \pm 0.6$ & $3.6 \pm 0.6$ & $3.7 \pm 0.6$ & 0.87 \\
\hline$p$ value & 0.14 & 0.01 & 0.13 & \\
\hline Serum $\mathrm{Na}(\mathrm{mEq} / \mathrm{L})$ day 1 & $137 \pm 7.2$ & $135 \pm 9.1$ & $131 \pm 25.9$ & 0.39 \\
\hline Serum $\mathrm{Na}(\mathrm{mEq} / \mathrm{L})$ day 7 & $133 \pm 5.5$ & $135 \pm 7.1$ & $138 \pm 5.7$ & 0.07 \\
\hline$p$ value & 0.11 & 0.89 & 0.42 & \\
\hline Serum $\mathrm{Ca}(\mathrm{mEq} / \mathrm{L})$ day 1 & $9.7 \pm 7.2$ & $7.6 \pm 9.1$ & $7.9 \pm 25.9$ & 0.40 \\
\hline Serum $\mathrm{Ca}(\mathrm{mEq} / \mathrm{L})$ day 7 & $7.6 \pm 0.7$ & $7.6 \pm 1.0$ & $7.7 \pm 1.3$ & 0.98 \\
\hline$p$ value & 0.33 & 0.94 & 0.43 & \\
\hline Serum PO4 (mg/dL) day 1 & $4.0 \pm 1.4$ & $4.4 \pm 1.9$ & $4.2 \pm 1.4$ & 0.67 \\
\hline Serum PO4 $(\mathrm{mg} / \mathrm{dL})$ day 7 & $3.6 \pm 1.4$ & $3.6 \pm 1.6$ & $3.6 \pm 1.4$ & 0.99 \\
\hline$p$ value & 0.85 & 0.11 & 0.17 & \\
\hline Blood Hgb (g/dL) day 1 & $10.1 \pm 1.9$ & $10.2 \pm 2.1$ & $10.2 \pm 2.2$ & 0.98 \\
\hline Blood Hgb (g/dL) day 7 & $9.7 \pm 2.3$ & $9.3 \pm 2.3$ & $10.2 \pm 2.7$ & 0.45 \\
\hline$p$ value & 0.14 & 0.01 & 0.64 & \\
\hline Serum uric acid $(\mathrm{mg} / \mathrm{dL})$ day 1 & $4.7 \pm 2.3$ & $5.7 \pm 3.2$ & $6.2 \pm 4.6$ & 0.48 \\
\hline Serum uric acid $(\mathrm{mg} / \mathrm{dL})$ day 7 & $3.7 \pm 1.9$ & $6.1 \pm 3.3$ & $6.2 \pm 5.9$ & 0.14 \\
\hline$p$ value & 0.52 & 0.75 & 0.45 & \\
\hline Leukocytes day $1\left(10^{3}\right)$ & $13.1 \pm 6.4$ & $14.8 \pm 6.0$ & $11.8 \pm 5.3$ & 0.16 \\
\hline Leukocytes day $7\left(10^{3}\right)$ & $10.7 \pm 5.8$ & $12.8 \pm 6.5$ & $9.9 \pm 4.8$ & 0.21 \\
\hline$p$ value & 0.51 & 0.14 & 0.19 & \\
\hline Platelets day $1\left(10^{3}\right)$ & $206 \pm 149$ & $265 \pm 182$ & $279 \pm 169$ & 0.22 \\
\hline Platelets day $7\left(10^{3}\right)$ & $295 \pm 164$ & $266 \pm 144$ & $298 \pm 147$ & 0.71 \\
\hline$p$ value & 0.10 & 0.72 & 0.06 & \\
\hline
\end{tabular}




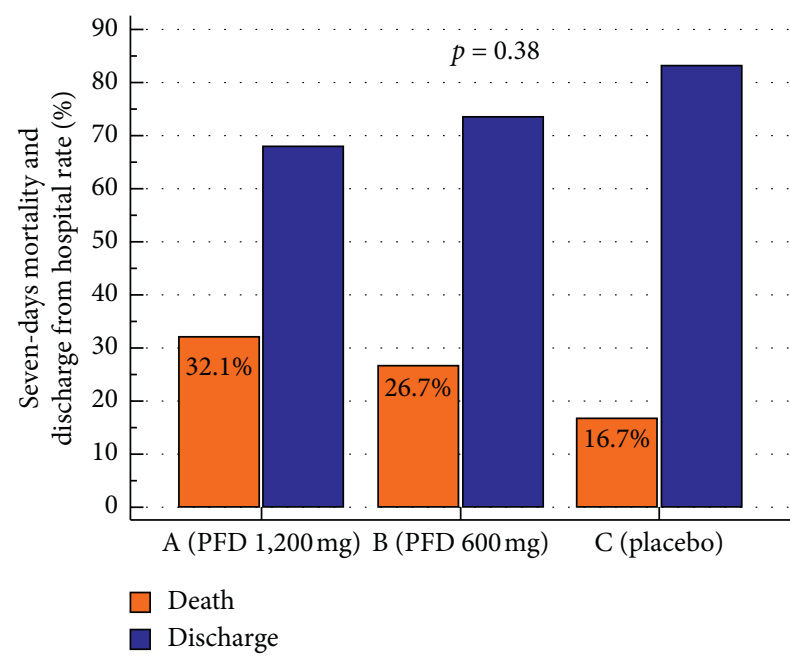

FIGURE 3: Mortality and discharge from hospital rate according to study groups.

improvement was observed in group B (PR-PFD, $600 \mathrm{mg} /$ day), as evidenced by a significant decrease in $\mathrm{sCr}$ by day 7 of the study, and plausible improvement event also observed in the placebo group.

In sepsis, there are extensive proinflammatory and antiinflammatory factors that change rapidly once sepsis develops [29]. Previous studies support an anti-inflammatory effect induced by PFD. In the nephrectomized rat model, PFD was effective in decreasing TNF- $\alpha$ and IL-6 levels, significantly decreasing proteinuria and NAG activity, attenuating interstitial fibrosis, and decreasing the expression of fibrotic markers and macrophage infiltration. PFD treatment significantly inhibited the expression of TNF- $\alpha$, IL-6, and nitric oxide synthase- 2 by M1 macrophages, suggesting its efficacy in the early and late periods of kidney damage [22]. The discrepancy between the study by Chen et al. and our findings regarding TNF- $\alpha$ levels could be explained by the etiology of AKI. We explored this event in human sepsis, which is considered a more robust inflammatory response than that in the nephrectomized model; another explanation could be the drug dosing and schedule of administration. To the best of our knowledge, this study is the first time that PR-PFD has been tested in SAKI, and unfortunately, we are not able to compare our findings with other clinical studies.

The primary action of PFD is the blockade of TGF- $\beta$. It seems reasonable to target TGF- $\beta$ during acute sepsis because the anti-inflammatory and immunoregulatory effects of TGF- $\beta$ involve activation of Smad7, and inhibition of renal inflammation is associated with marked upregulation of renal Smad7 and suppression of NF- $\kappa$ B activation to switch off the inflammatory response [23, 24].

As reported, PFD improved kidney function in a model of acute and chronic kidney disease in rats; PFD prevented the elevation of sCr and $\mathrm{BUN}$ in a remnant kidney model of chronic renal failure; histological findings revealed a decrease in interstitial fibrosis. These effects were mediated by the suppression of TGF- $\beta$ and fibronectin mRNA expression [23]. Shimizu et al. showed attenuation of renal damage in a rat model with unilateral obstruction during treatment with PFD and induced renal function recovery before removal of ureteral obstruction [24], and the same group also showed that PFD prevents collagen accumulation in the remanent kidney in rats with partial nephrectomy [25]. However, septic AKI could have another physiopathological mechanism and may differ in the response to the same drug.

Apoptosis has been shown to play a role in the pathogenesis of sepsis nephrotoxicity, and PFD was shown to ameliorate fibrosis [30]. Shihab et al. evaluated the effect of PFD on the expression of apoptosis-regulatory genes in the kidneys of CsA-treated rats. PFD significantly ameliorated nephrotoxicity, and the number of apoptosis-positive cells was reduced by PFD treatment. In addition, PFD downregulated the mRNA expression of CsA-induced p53 and Fas-ligand and increased that of $\mathrm{Bcl}-\mathrm{xL}$, which was previously reduced by CsA. Finally, PFD significantly downregulated caspase 3 expression, presented mostly on renal tubular epithelial cells. The authors concluded that PFD could have an antiapoptotic effect [26].

Perhaps PR-PFD (or the dose we implemented) was not sufficient to improve outcomes in sAKI even if there was a plausible effect and maybe the negative effect of PFD $600 \mathrm{mg}$ in our study may be because it did not reach a clinical target dose concentration. Previous trials have demonstrated that, in septic AKI patients, there is a lack of evidence for the improvement of outcomes with well-established therapies. For instance, early goal-directed therapy is not beneficial to renal function, i.e., aggressive fluid loading with a positive fluid balance is not beneficial to renal function and may even be injurious, and artificial colloids could be harmful to the kidney [17].

We realize that our study has the following limitations: this was a single-center study, the sample population was small, and we did not take into account the urinary output to classify AKI; the statistical analysis may have been underpowered for the primary and secondary outcomes; and finally, follow-up was limited to 7 days. Due to these limitations, we know that these results cannot be generalized to other populations.

On the other hand, this study is the first time that PR-PFD has been used to explore the potential improvement in septic AKI patients. Despite our negative results, we believe that PFD should be explored in future studies, and there is evidence of improvement in inflammation and fibrosis processes, which are fundamental in the pathogenesis of AKI [22-26].

\section{Conclusion}

In conclusion, in septic AKI patients, PR-PFD for 7 days did not improve kidney function when compared with placebo, and it was safe in terms of adverse events. Further studies are needed to confirm our results.

\section{Data Availability}

The data used to support this trial can be found at the Nephrology service of the Civil Hospital of Guadalajara Fray Antonio Alcalde. 


\section{Ethical Approval}

This study was approved by the Hospital Civil de Guadalajara Fray Antonio Alcalde Ethics Committee (HCG/CI0049/15) and by Comision Federal para la Proteccion de Riesgos Sanitarios (COFEPRIS), México. The trial was presented according to the CONSORT 2010 Explanation and Elaboration guide.

\section{Consent}

Written informed consent was obtained from all study participants.

\section{Conflicts of Interest}

The authors declare that they have no conflicts of interest.

\section{Authors' Contributions}

JSCI, GGG, JAB, and LGB contributed to the conception, design, execution, and analysis of the trial. MIE contributed to the statistical analysis, and JLP contributed with the analysis of the serum samples and the execution of the trial.

\section{Acknowledgments}

The authors would like to thank Dr. Adriana Salazar-Montes and Dr. Silvia Lucano for the substantive contributions to the research and for the administrative work at the beginning of the research and Dr. Graciela Tapia for helping with the analysis of data.

\section{References}

[1] N. H. Lameire, A. Bagga, D. Cruz et al., "Acute kidney injury: an increasing global concern," The Lancet, vol. 382, no. 9887, pp. 170-179, 2013.

[2] E. D. Siew and A. Davenport, "The growth of acute kidney injury: a rising tide or just closer attention to detail?," Kidney International, vol. 87, no. 1, pp. 46-61, 2015.

[3] R. Murugan, V. Karajala-Subramanyam, M. Lee et al., "Acute kidney injury in non-severe pneumonia is associated with an increased immune response and lower survival," Kidney International, vol. 77, no. 6, pp. 527-535, 2010.

[4] S. Nisula, K. M. Kaukonen, K.-M. Kaukonen et al., "Incidence, risk factors and 90-day mortality of patients with acute kidney injury in Finnish intensive care units: the FINNAKI study," Intensive Care Medicine, vol. 39, no. 3, pp. 420-428, 2013.

[5] S. M. Bagshaw, C. George, I. Dinu, and R. Bellomo, "A multicentre evaluation of the RIFLE criteria for early acute kidney injury in critically ill patients," Nephrol Dial Transplant, vol. 23, no. 4, pp. 1203-1210, 2008.

[6] M. Ostermann and R. W. S. Chang, "Acute kidney injury in the intensive care unit according to RIFLE," Critical Care Medicine, vol. 35, no. 8, pp. 1837-1843, 2007.

[7] E. A. Hoste, G. Clermont, A. Kersten et al., "RIFLE criteria for acute kidney injury are associated with hospital mortality in critically ill patients: a cohort analysis," Critical Care, vol. 10, no. 3, p. R73, 2006.

[8] E. A. J. Hoste, S. M. Bagshaw, R. Bellomo et al., "Epidemiology of acute kidney injury in critically ill patients: the multinational AKI-EPI study," Intensive Care Medicine, vol. 41, no. 8, pp. 1411-1423, 2015.

[9] J.-L. Vincent, Y. Sakr, C. L. Sprung et al., "Sepsis in European intensive care units: results of the SOAP study," Critical Care Medicine, vol. 34, no. 2, pp. 344-353, 2006.

[10] J. Case, S. Khan, R. Khalid, and A. Khan, "Epidemiology of acute kidney injury in the intensive care unit," Critical Care Research and Practice, vol. 2013, Article ID 479730, 9 pages, 2013.

[11] L. S. Chawla, R. L. Amdur, S. Amodeo, P. L. Kimmel, and C. E. Palant, "The severity of acute kidney injury predicts progression to chronic kidney disease," Kidney International, vol. 79, no. 12, pp. 1361-1369, 2011.

[12] H. E. Wang, P. Muntner, G. M. Chertow, and D. G. Warnock, "Acute kidney injury and mortality in hospitalized patients," American Journal of Nephrology, vol. 35, no. 4, pp. 349-355, 2012.

[13] A. Zarjou and A. Agarwal, "Sepsis and acute kidney injury," Journal of the American Society of Nephrology, vol. 22, no. 6, pp. 999-1006, 2011.

[14] H. Gomez, C. Ince, D. De Backer et al., "A unified theory of sepsis-induced acute kidney injury," Shock, vol. 41, no. 1, pp. 3-11, 2014.

[15] R. L. Mehta, J. Bouchard, J. Bouchard et al., "Sepsis as a cause and consequence of acute kidney injury: program to improve care in acute renal disease," Intensive Care Medicine, vol. 37, no. 2, pp. 241-248, 2011.

[16] E. Peters, M. Antonelli, X. Wittebole, R. Nanchal, B. François, and Y. Sakr, "A worldwide multicentre evaluationn of the influence of deterioration or improvement of acute kidney injury on clinical outcome in critically ill patients with and without sepsis at ICU admission: results from the intensive care over nations audit," Critical Care, vol. 22, p. 188, 2018.

[17] R. Bellomo, J. A. Kellum, C. Ronco et al., "Acute kidney injury in sepsis," Intensive Care Medicine, vol. 43, no. 6, pp. 816-828, 2017.

[18] H. Gómez and J. A. Kellum, "Sepsis-induced acute kidney injury," Current Opinion in Critical Care, vol. 22, no. 6, pp. 546-553, 2016.

[19] S. Dellepiane, M. Marengo, and V. Cantaluppi, "Detrimental cross-talk between sepsis and acute kidney injury: new pathogenic mechanisms, early biomarkers and targeted therapies," Critical Care, vol. 20, p. 61, 2016.

[20] F. Mariano, V. Cantaluppi, M. Stella et al., "Circulating plasma factors induce tubular and glomerular alterations in septic burns patients," Critical Care, vol. 12, no. 2, p. R42, 2008.

[21] P. Pickkers, M. Ostermann, M. Joannidis et al., "The intensive care medicine agenda on acute kidney injury," Intensive Care Medicine, vol. 43, no. 9, pp. 1198-1209, 2017.

[22] J.-F. Chen, H.-F. Ni, M.-M. Pan et al., "Pirfenidone inhibits macrophage infiltration in 5/6 nephrectomized rats," American Journal of Physiology-Renal Physiology, vol. 304, no. 6, pp. F676-F685, 2013.

[23] W. Wang, X. R. Huang, A. G. Li et al., "Signaling mechanism of TGF- $\beta 1$ in prevention of renal inflammation: role of Smad7," Journal of the American Society of Nephrology, vol. 16, no. 5, pp. 1371-1383, 2005.

[24] T. Shimizu, T. Kuroda, S. Hata, M. Fukagawa, S. B. Margolin, and K. Kurokawa, "Pirfenidone improves renal function and fibrosis in the post-obstructed kidney," Kidney International, vol. 54, no. 1, pp. 99-109, 1998.

[25] T. Shimizu, M. Fukagawa, T. Kuroda et al., "Pirfenidone prevents collagen accumulation in the remnant kidney in rats 
with partial nephrectomy," Kidney International, vol. 63, pp. S239-S243, 1997.

[26] F. S. Shihab, W. M. Bennett, H. Yi, and T. F. Andoh, "Effect of pirfenidone on apoptosis-regulatory genes in chronic cyclosporine nephrotoxicity," Transplantation, vol. 79, no. 4, pp. 419-426, 2005.

[27] J. A. Kellum, N. Lameire, and KDIGO AKI Guideline Work Group, "Diagnosis, evaluation, and management of acute kidney injury: a KDIGO summary (part 1)," Critical Care, vol. 17, no. 1, p. 204, 2013.

[28] M. Singer, C. S. Deutschman, C. W. Seymour et al., "The third international consensus definitions for sepsis and septic shock (Sepsis-3)," Journal of the American Medical Association, vol. 315, no. 8, pp. 801-810, 2016.

[29] S. Nullens, J. De Man, C. Bridts, D. Ebo, S. Francque, and B. De Winter, "Identifying therapeutic targets for sepsis research: a characterization study of the inflammatory players in the cecal ligation and puncture model," Mediators of Inflammation, vol. 2018, no. 5, 17 pages, Article ID 5130463, 2018.

[30] E. Gagliardini and A. Benigni, "Therapeutic potential of TGF$\beta$ inhibition in chronic renal failure," Expert Opinion on Biological Therapy, vol. 7, no. 3, pp. 293-304, 2007. 